\title{
Shape forming of ceramics via gelcasting of aqueous particulate slurries
}

\author{
S DHARA, R K KAMBOJ, M PRADHAN and P BHARGAVA* \\ Materials Science Centre, Indian Institute of Technology, Kharagpur 721 302, India
}

\begin{abstract}
Gelcasting is a promising technique for shape forming of bulk dense or porous ceramic, metal structures. The process offers a number of advantages over processes such as slip casting, injection molding in forming complex ceramic shapes. It is shown here that the optimization of slurry rheology, choice of mold material, mold design and the drying conditions have a significant role in the overall success of the process. In this process, components of simple or complex shapes can be produced to near net shape by direct casting. If required complex shapes can also be produced by machining the green gelcast bodies. The process of gelcasting also has a lot of potential in forming highly porous ceramic shapes.
\end{abstract}

Keywords. Near net shape; green machining; gelcasting; ceramic foam; complex shape.

\section{Introduction}

In the past few years, the gelcasting technique has caught the attention of many researchers all over the world for its simplicity and the advantages it offers over other ceramic manufacturing techniques (Omatete et al 1991, 1997; Janney et al 1998). Gelcasting is also particularly suited for custom manufacturing since there is no need for creating any specialized facilities.

In the initial period after its invention, the process did not appear very attractive from an industrial viewpoint due to its use of toxic organic additives. Recent study by Janney et al (1998) reported that methacrylamide (MAM) with methylene bisacrylamide (MBAM) as monomer and cross-linker were suitable for aqueous gelcasting and were much lower in toxicity as compared to the previously used acrylamides (Omatete et al 1991). For aqueous slurries made using MAM-MBAM, ammonium persulphate (APS) and tetra methyl ethylene diamine (TEMED) serve as the initiator and catalyst, respectively.

Besides the simplicity and capability of forming near net complex shapes, a number of studies have demonstrated the large number of advantages for conventional gelcasting based on the MAM-MBAM system. Although, the gelcast ceramic samples have low binder content (3$4 \mathrm{wt} \%$ ), they possess sufficient strength to permit machining in the green state (Nunn and Kirby 1996; Kamboj et al 2002). Gelcasting has been used for a wide variety of materials including metals, ceramics, alloys and composites. Gelcasting has also been successfully used in making highly porous ceramics by direct foaming techniques (Sepulveda 1997). The foamed gelcasting suspensions are cast to form net shape porous ceramic shapes.

\footnotetext{
*Author for correspondence
}

The present study attempts to highlight the use of gelcasting in forming simple and complex dense ceramic components with a wide range of shapes and sizes. The process has great potential in fabrication of net shaped highly porous ceramics as demonstrated in the study.

\section{Experimental}

\subsection{Slurry preparation}

A $15 \mathrm{wt} \%$ aqueous solution of monomer (MAM) and cross-linker (MBAM) in 6:1 ratio was used as premix for slurry preparation. During slurry preparation, alumina powder (Alcoa CT $3000 \mathrm{SG}, d_{50} \approx 0.7 \mu \mathrm{m}$, surface area, $7 \mathrm{~m}^{2} / \mathrm{g}$ ) was added in steps to attain the desirable solids loading of $55 \mathrm{vol} \%$. A dispersant, polyacrylic acid ammonium salt (Darvan $821 \mathrm{~A}$ ) was added in quantity of $1 \mathrm{ml}$ per $100 \mathrm{~g}$ of powder to the premix. The slurries were prepared in polypropylene bottles using zirconia milling media of $\sim 3 \mathrm{~mm}$ diameter with $1 \cdot 3: 1$ weight ratio of powder to milling media. All slurries were milled/mixed for a period of $24 \mathrm{~h}$.

For producing dense components deairing is essential before casting to avoid defect in the component. After $24 \mathrm{~h}$ of milling, the slurry was filtered using plastic sieve to separate the grinding media and optimum amount of antifoaming agent was added followed by rolling for $30 \mathrm{~min}$ to eliminate the air bubbles, which were generated and or introduced during slurry preparation via milling. Through preliminary experiments, $0 \cdot 1$ vol.\% of 1 -octanol was found to be highly effective for deairing.

A manually controlled co-axial cylinder viscometer (Brookfield, Model RVT/73232) with shear rates varying from $0 \cdot 5-46 \cdot 5 \mathrm{~s}^{-1}$ was used for rheological characterization of the slurries. Relative suspension height measurements were used to evaluate the slurry stability. 
For fabrication of porous ceramics, the slurries were prepared as described earlier and following slurry preparation, $1 \mu \mathrm{l}$ of cetyl tri-methyl ammonium bromide (CTMAB), a foaming agent was added per $\mathrm{ml}$ of the slurries. The slurries were foamed by tumbling the bottles containing the zirconia media. Following foaming, the samples were cast in petroleum jelly coated molds and were stored at ambient temperature under high humidity conditions for $\sim 8 \mathrm{~h}$ to allow gelation. The samples were then dried in an oven preheated to $40^{\circ} \mathrm{C}$.

\subsection{Casting and gelation}

The choice of mold materials and the design was made as per the component details. A mold release agent (white petroleum jelly) was used to encourage easy release of the components. Initiator (10 $\mathrm{wt} \%$, APS) solution and catalyst - TEMED, $1 \mu \mathrm{l}$ and $0.5 \mu \mathrm{l}$ per $\mathrm{g}$ of slurry, respectively were added and mixed to homogeneity. The slurry was poured into the mold and the mold was kept in a preheated oven at $60^{\circ} \mathrm{C}$ for $30 \mathrm{~min}$. The mold was removed from the oven and the part was unmolded.

For forming porous ceramics, the cast-foamed slurries were allowed to gel at ambient conditions. Use of high temperature was detrimental to the stability of foams.

All samples were dried under controlled humidity conditions, followed by binder burn out and pre-sintering in the same cycle at $600^{\circ} \mathrm{C}$ and $900^{\circ} \mathrm{C}$, respectively and sintering at $1600^{\circ} \mathrm{C}$ for $2 \mathrm{~h}$.

\section{Results and discussion}

\subsection{Slurry characteristics}

The alumina slurries were characterized by measuring viscosity and relative suspension height measurements. The slurries were shear thinning in behaviour with minimum viscosity of $9.5 \mathrm{~Pa}$.s at shear rate $0.5 \mathrm{~s}^{-1}$ with $1 \mathrm{ml}$ Darvan 821A per $100 \mathrm{~g}$ of powder. RSH data revealed that the 1 vol.\% alumina suspension with $1 \mathrm{ml}$ Darvan $821 \mathrm{~A}$ per $100 \mathrm{~g}$ powder took more than 24 days to settle which indicated the suspension was quite stable.

\subsection{Gelcasting}

3.2a Molds: Since gelcasting is a low temperature process (ambient, $80^{\circ} \mathrm{C}$ ) and it needs impermeable molds, a variety of mold materials such as aluminum, stainless steel, plastic, glass and wax molds can be used. Properties of the mold materials coupled with the mold design play a significant role in forming of complex shapes, as it must allow shrinkage to occur and minimize stresses in the cast part during drying. These problems can often be addressed by use of softer mold materials that can deform under the stresses developed due to drying shrinkage. Additionally, the core of the molds may be made hollow to meet the above requirements.

Fabrication of complex shapes may also pose problems during removal of the part from the mold following gelation. The use of materials like wax, which can be selectively dissolved away following gelation, is preferable for making molds for casting complex shapes.

In the present study, for fabrication of the complex shaped components like turbine rotor, soft wax molds were used which were dissolved in the process of releasing the cast component. For other shapes aluminum, steel or plastic molds were used (figure 1(a)). From the experience acquired in casting large number of components, it can be concluded that the permanent molds must be of the split nature, which can be disassembled with minimum relative motion between cast part and the mold surfaces during unmolding. If the design of the component permits, it is preferred that the gelcasting molds be of closed type. There should not be any vent or leakage in the closed mold design, which may be a potential site for enhanced drying causing non-uniformities or curvature development in the parts.
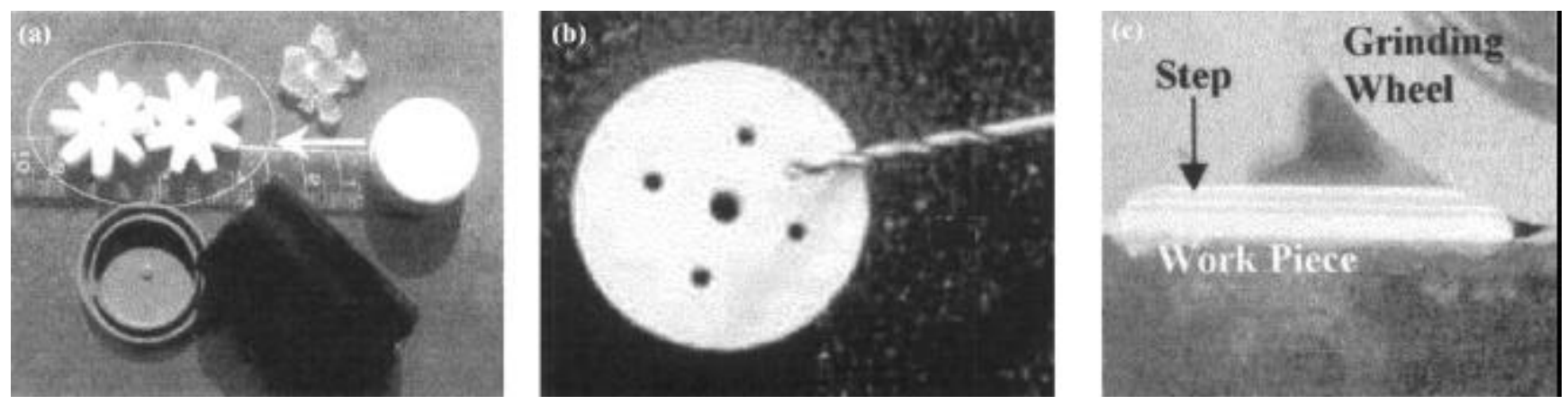

Figure 1. (a) Gears produced by machining of as cast circular disks with a razor blade, (b) holes drilled into a dried green gelcast sample using a HSS drill bit and (c) steps machined on a dried green gelcast sample using a carborundum silicon carbide grinding wheel. 
3.2b Casting and gelation: In this study $1 \mu \mathrm{l}$ of APS solution and $0.5 \mu \mathrm{l}$ TEMED was added per $\mathrm{g}$ of the alumina suspensions for gelation of the slurry at $60^{\circ} \mathrm{C}$ in oven. For room temperature gelation, $4 \mu \mathrm{l}$ of APS solution and $1 \mu \mathrm{l}$ of TEMED were added per $\mathrm{g}$ of suspension and the sample was kept in closed environment to prevent drying during gelation.

3.2c Drying: Drying is one of the most critical steps in gelcasting. During drying long samples were seen to develop curvature, which was maintained in sintered bars. Sometimes non-uniformities in drying led to cracks in green samples, which were not visible in the green state but resulted in cracked sintered samples. To avoid the crack formation, the samples were dried initially at high humidity $(85-90 \%)$ at constant temperature, $50^{\circ} \mathrm{C}$, and the humidity was gradually reduced to around $50 \%$. Finally, the samples were dried under high vacuum. It was observed that extremely high relative humidity values of over $95 \%$ resulted in water condensation over the samples, causing separation of the top layer during sintering.

\section{2d Fabrication of simple and complex bulk ceramic} shapes: Gelcasting can be used to form near net shapes in a single step or by machining simple shapes into more complex ones. Figure 1(a) shows a pair of alumina gears machined from as cast green ceramic disks produced by casting in plastic containers used for packaging photo-
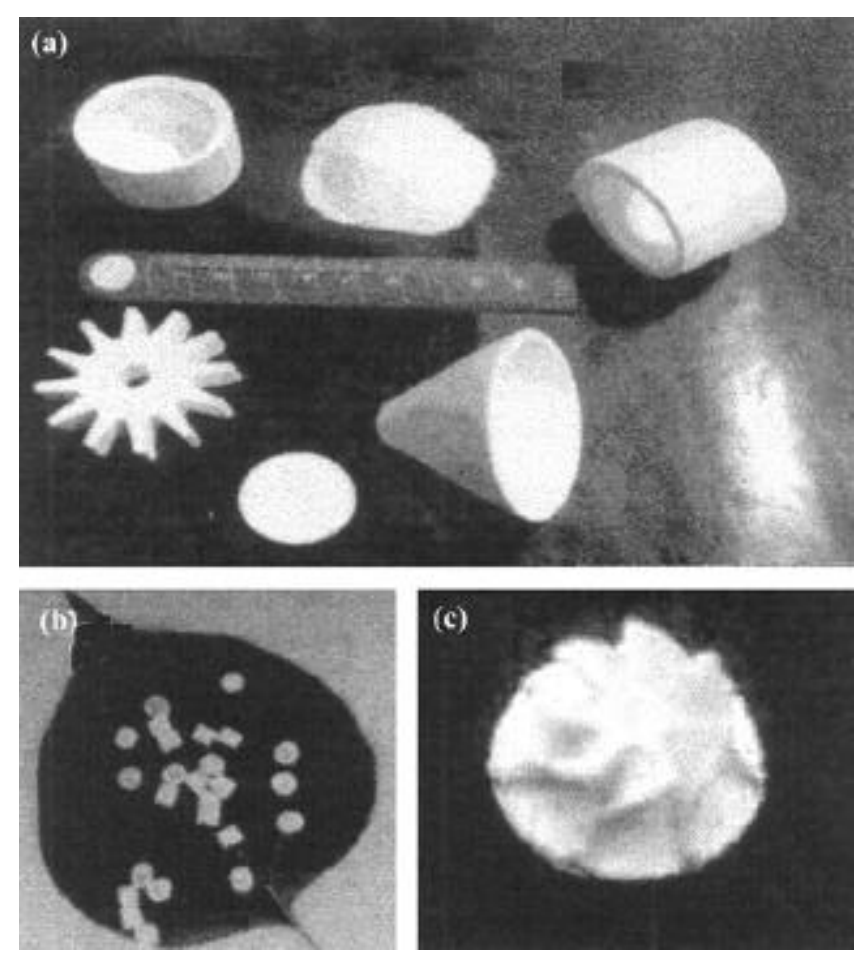

Figure 2. (a) Near net shape alumina components produced directly by gelcasting using plastic or metal or glass molds, (b) crucibles for thermal analysis applications made using stainless steel mold and (c) turbine rotor made using wax mold. graphic film roll. The gears were machined simply by using razor blades before any drying could occur. Dried gelcast samples are also usually strong enough to be green machined into various shapes. All gelcast samples could be drilled easily using carbide tools, without causing defects as shown in figure 1(b). Figure 1(c) shows a step produced by grinding of green gelcast sample (Kamboj 2000).

In the present study, a variety of other components were produced to near net shapes to demonstrate the potential of gelcasting in manufacturing shapes for different applications (figure 2(a)). The components made spanned a wide range of sizes. The smallest component made was a cylindrical alumina crucible of the following dimensions: $5 \mathrm{~mm}$ outer diameter, $4 \mathrm{~mm}$ height and $1 \mathrm{~mm}$ wall thickness (figure 2(b)). On the other hand, a large flat alumina plate $145 \times 109 \times 3 \mathrm{~mm}$ was made successfully by gelcasting. The most complex shaped components of all was the turbine rotor with thin curved blades (figure 2(c)).

\subsection{Fabrication of porous ceramics}

It was seen that the foaming rate was higher for lower solids loading slurries while the foam stability was greater for higher solids loading slurries. For 45 vol.\% alumina slurry which had $1 \mu \mathrm{l}$ of $10 \mathrm{wt} \%$ CTMAB solution per $\mathrm{ml}$ of slurry, the foam height increased to 8 times its original after $7 \mathrm{~h}$ of tumbling. While 55 vol.\% slurries with a similar amount of foaming agent resulted in increase in foam height to 4.7 times after $7 \mathrm{~h}$ of tumbling.

It is to be noted that there was a critical amount of foaming agent for different solids loading in the slurry beyond which the slurries were coagulated so that the slurries could not be foamed at all due to their ionic nature. For example, for a 55 vol.\% solids loading of the slurry, use of $40 \mu$ of CTMAB $10 \mathrm{wt} \%$ solution in $15 \mathrm{ml}$ slurry resulted in instantaneous coagulation while $35 \mu$ l gave well-foamed slurry.

Gelation and development of strength for green gelcast foams are very critical issues here. Gelation of foamed ceramic slurries is inhibited as compared to that of bulk
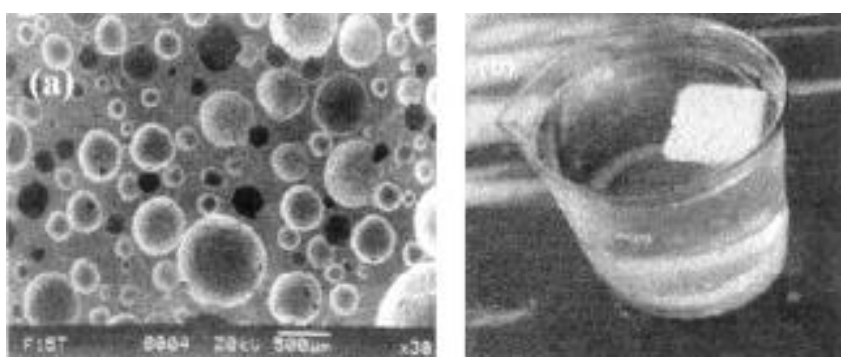

Figure 3. (a) Microstructure of a porous alumina made via gel casting and (b) a piece of the porous alumina floating on water. 
samples due to large volume or surface of the slurry, which is exposed to air (oxygen). Even if gelation (polymerization) takes place the foamed ceramic slurries, which have $80 \%$ or higher volume percentage of air, may be easily deformed upon application of shear force. It is essential that the foamed, gelled ceramic slurries be dried for development of strength.

For gelation of foamed slurries, the amount of initiator (APS) and catalyst (TEMED) used was about 3-4 times the amount used for regular slurries for forming dense parts. This was due to difficulties in mixing as well as presence of large amount of atmospheric oxygen which acts as inhibitor for the free radical reaction. The foamed slurries had to be gelled at room temperature as higher temperature starts to disrupt the foam structure. Even after several hours of addition of the initiator and the catalyst to promote gelation, it is difficult to determine if it has actually gelled by mechanically sensing the cast slurry. This difficulty is enhanced due to the large amount of air, which makes the effective modulus of the cast very low. The gelcast ceramic foams were sintered at $1600^{\circ} \mathrm{C}$ for $2 \mathrm{~h}$ to attain reasonably dense struts. Samples produced by the above technique had porosity up to $80 \%$ (figure 3 ). The foamed slurries can be cast into cylindrical, rectangular or flat plates using appropriate petroleum jelly coated molds. It was seen that incorporation of features in bulk shapes by use of cores within the molds was difficult as the cores restricted the drying shrinkage resulting in macro cracks.

\section{Summary}

During the gelcasting process the parts are most susceptible to cracking during the drying step. Thus, it is essential to use highly loaded ceramic slurries to reduce the drying shrinkage and thus minimize stresses, which typically cause cracking or curvature development in sintered parts. The gelcast slurries must be well de-aired prior to casting to avoid defects due to entrapped air bubbles. Fabrication of defect free gelcast parts also significantly depends on the mold material, surface finish and design of molds. For highly complex shapes soft mold materials like wax are preferable. It is desirable that the cores in molds be made as compliant as possible so that they do not offer resistance to shrinking parts during drying. In general, split nature of molds always facilitates release of the cast parts.

Gelcasting can be used to form simple or complex shaped components in a single step or by machining of simple disks, blocks etc. Features such as steps, through and through holes can be incorporated after net shape forming. Thus, complexity in mold design is minimized and mold release is made easier. There is almost no limitation to the size of the parts formed and it can be used with a range of materials as long as the material forms a stable suspension. The gelcasting process can also be used to form highly porous ceramic shapes by direct foaming technique.

\section{Acknowledgement}

Financial support from CSIR (Project No. 03(0917)/00/ EMR-II) and DST (Project No. SR/FTP/ET-72/2000) is thankfully acknowledged.

\section{References}

Janney M A, Omatete O O, Walls C A, Nunn S D, Ogle R J and Westmoreland G 1998 J. Am. Ceram. Soc. 81581

Kamboj R K 2000 Fabrication of complex shapes and machinability of green gelcast ceramics, M.Tech. Thesis, IIT Kharagpur

Kamboj R K, Dhara S and Bhargava P 2002 J. Eur. Ceram. Soc. (in press)

Nunn S D and Kirby G H 1996 Ceram. Engg. Sci. Proc. 17209

Omatete O O, Janney M A and Strehlow R A 1991 Am. Ceram. Soc. Bull. 701641

Omatete O O, Janney M A and Nunn S D 1997 J. Eur. Ceram. Soc. 17407

Sepulveda P 1997 Am. Ceram. Soc. Bull. 7661 